\title{
Morning akinesia in Parkinson's disease: challenges and solutions
}

This article was published in the following Dove Press journal:

Journal of Parkinsonism and Restless Legs Syndrome

15 June 2016

Number of times this article has been viewed

\author{
Nicola Tambasco' \\ Simone Simoni' \\ Pasquale Nigro' \\ Federico Paolini Paoletti ${ }^{1}$ \\ Erica Marsili' \\ Paolo Calabresi ${ }^{1,2}$ \\ 'Neurology Clinic, Azienda \\ Ospedaliera - Università di \\ Perugia, Perugia, ${ }^{2}$ Neurophysiology \\ Department, IRCCS Fondazione Santa \\ Lucia, Rome, Italy
}

\begin{abstract}
Motor complications of Parkinson's disease (PD) have been reported to occur after a few years of treatment with levodopa (L-dopa). Morning akinesia is a delayed ON of the first L-dopa daily dose, occurring in almost $60 \%$ of patients on dopaminergic treatment. This is primarily a motor symptom, but has been recently recognized as being correlated with nonmotor fluctuations. Sleep disorders and gastrointestinal dysfunction might be the underlying mechanisms. Over the past 30 years, several pharmacological and nonpharmacological approaches have been investigated.
\end{abstract}

Keywords: Parkinson's disease, morning akinesia, motor fluctuation, L-dopa

\section{Introduction}

Most patients with Parkinson's disease (PD) on levodopa (L-dopa) have motor fluctuations. An improvement in symptoms after L-dopa administration is defined as "ON", whereas a return to symptoms is termed "OFF", ie, when L-dopa (L-dopa) plasma concentration decreases. OFF periods generally appear when the benefit from a given L-dopa dose disappears prematurely (wearing OFF) or when the next L-dopa dose produces a delayed onset of action (delayed ON). ${ }^{2,3}$ Delayed ON of the first L-dopa daily dose is known as morning akinesia, and this condition can significantly affect the quality of life (QoL) and impair daily activities, such as arising from bed, dressing, bathing, toileting, preparing breakfast, and getting on with the day's work. ${ }^{2}$ Morning akinesia is the most common, and often, the first motor complication of PD. ${ }^{2}$ It is noticed at awakening after a nightlong treatment-free period, reflecting the dopaminergic nocturnal decline with insufficient nighttime storage or refreshing of the dopaminergic system during nighttime and sleep.

Over the past 3 decades, several investigations have been carried out to understand this symptomology.

\section{Pathophysiology}

Morning akinesia occurs in almost $60 \%$ of PD patients on dopaminergic treatment across all disease stages. ${ }^{3}$ Most of these patients have experienced longer durations of PD motor symptoms and are in moderate to advanced stages of disease, with the largest proportion of these patients classified according to the Hoehn and Yahr scale 2.5-3). ${ }^{3}$

OFF periods are mainly characterized by motor symptoms and motor complications, although they have been recently attributed to nonmotor OFF and nonmotor fluctuations. . $^{3,4}$ 
The optimization of dopaminergic treatment is also crucial. Peripheral and central factors underlie these fluctuations.

\section{The emerging role of nonmotor aspects}

Nonmotor symptoms (NMSs) are often poorly understood and inadequately treated, but are thought to arise from a more diffused involvement of the central, autonomic, and enteric nervous systems. ${ }^{5}$

The relevance of NMSs has recently been studied in 320 PD patients, ${ }^{3}$ with $88 \%$ of the patients reporting an association between morning akinesia and NMSs.

The predominant NMSs associated with morning akinesia are urgency of urination, anxiety, dribbling of saliva, pain, low mood, limb paresthesia, and dizziness.

Sleep disorders are often involved in triggering early morning OFF periods. PD patients have been reported to have reduced total sleep times compared to healthy controls. ${ }^{6}$ Sleep efficiency is often reduced, with an increased number of awakenings and an increased wakefulness after sleep onset. Sleep fragmentation is the most consistent and often the earliest sleep disturbance in $\mathrm{PD}$, with frequent awakenings during the night, with often $30-40 \%$ of the time being awake. Up to $80 \%$ of PD patients report having $2-5$ awakenings per night. ${ }^{7,8}$ Sleep disruption, thus, may easily promote the appearance of nightlong rigidity and prolonged muscle contractions.

The role of sleep in early morning motor disturbances has not yet been clarified. In a recent study, $10-55 \%$ of patients with mild to moderate $\mathrm{PD}$ and a fluctuating response to L-dopa experienced a reduction in disability for $40-60$ minutes after waking. ${ }^{9}$ This improvement before drug intake is known as sleep benefit, and may be due to an improvement in dopaminergic function during sleep. Other "pharmacologic hypotheses" implicate drug-induced motor fluctuations, ${ }^{7}$ transient worsening after the first morning L-dopa dose, ${ }^{10}$ and a competition between large neutral amino acids and L-dopa for transport access into the brain. ${ }^{8,11}$

Other symptoms have been recently associated with morning akinesia, including post-prandial bloating, abdominal discomfort, early satiety, nausea, vomiting, weight loss, and malnutrition, ${ }^{12,13}$ or in other words, gastroparesis is a consistent feature of gastrointestinal dysfunction (GId). ${ }^{14}$

GId in PD is due to both the underlying synucleinopathy and dopaminergic therapy. ${ }^{15}$ Data suggest that the underlying neurodegenerative process affects the central, autonomic, and enteric nervous systems. Features of GId include dry mouth, sialorrhoea, dysphagia, oesophageal dysmotility, gastrooesophageal reflux, gastroparesis, constipation, and impaired defecation. ${ }^{12}$ These gastrointestinal symptoms significantly impair QoL in PD. ${ }^{16}$

Gastroparesis, a condition where the stomach takes longer than normal to empty, is common in both early and advanced PD patients, and may even be a marker of preclinical PD. ${ }^{17}$ Nonetheless, data concerning prevalence, relationship to the underlying disease process, relevance to PD management, and optimal treatment of gastroparetic symptoms are still limited. ${ }^{13}$ In addition to causing gastrointestinal symptoms, gastroparesis may cause motor fluctuations, including delayed $\mathrm{ON}$ and morning akinesia, by delaying the arrival of oral L-dopa to intestinal absorptive sites. ${ }^{12,14,18-21}$

To guarantee a high level of efficacy from oral L-dopa, it must be taken on an empty stomach so that it can be absorbed into the proximal small intestine. Gastroparesis can cause a delay in L-dopa delivery to the duodenum, resulting in the clinical phenomenon of delayed ON after a L-dopa dose. ${ }^{18}$ Several studies have demonstrated a significant relationship between gastric emptying and L-dopa pharmacokinetics in PD patients, suggesting that delayed gastric emptying contributes to delayed ON and other motor fluctuations. ${ }^{22-24}$

Other drugs, including dopamine agonists, anticholinergics, amantadine, inhibitors of monoamine oxidase and catechol-O-methyltransferase (COMT), may also contribute to GId. ${ }^{25}$ L-dopa can increase gastric acid secretion, impair gastric relaxation, and delay gastric emptying: ${ }^{14,26,27}$ anticholinergics and amantadine commonly cause dry mouth and constipation; and COMT inhibitors can cause diarrhoea.

The association between morning akinesia and other common NMSs which strongly impair health-related QoL, such as fatigue, pain, and psychiatric disturbances, ${ }^{4}$ needs to be investigated. Nevertheless, improving NMSs should be viewed as an important part in the management of PD., ${ }^{4,28}$

It has also been shown that regardless of the disease duration or severity of motor complications, not a single NMS but the burden of "total" NMSs is the major determinant of QoL. ${ }^{28}$ Some symptoms such as fatigue, depression, and concentration problems seem to contribute to this burden more than others, since these occur both in "ON" and "OFF" periods. Fatigue has emerged as a key NMS of PD, and its prevalence reached almost $50 \%$ even in patients with early PD. ${ }^{4}$

\section{Challenges and solutions}

Since the first descriptions of L-dopa-induced complications, ${ }^{29,30}$ delayed ON, sleep disorders, and early morning OFF periods have always been controversial issues. Specifically, 
the optimization of traditional pharmacologic PD oral therapy by itself may not be sufficient for alleviating symptoms.

Although it has been reported that $50 \%$ to $80 \%$ of PD patients develop motor complications within 5 to 10 years from the beginning of L-dopa therapy, ${ }^{29}$ recent studies state that $\sim 50 \%$ of patients show motor complications within 2 years of treatment. ${ }^{31,32}$

Standard oral L-dopa treatment is inadequate for the treatment of morning akinesia for reasons related to its pharmacodynamics and pharmacokinetics and because have a short half-life, erratic gastrointestinal absorption, and competitive transport across the blood-brain barrier.

L-dopa has a very poor solubility and its "end-of-dose" deterioration is directly related to the level of plasma L-dopa. Therefore, one of the first strategies attempted to focus on prolonging L-dopa plasma levels, using long-acting, controlled-release L-dopa preparations. ${ }^{33-36}$ Nevertheless, due to delayed gastric emptying, an oral dose of L-dopa may remain in the stomach for a long time before being absorbed in the small intestine. ${ }^{33-36}$

Another approach is administering L-dopa as a liquid solution to reduce gastric transit time and improve the onset of effect. This approach may be beneficial for some patients with severe fluctuations; however, the clinical benefits of liquid L-dopa compared with tablets has not been confirmed in controlled clinical studies. ${ }^{37}$ To manage early morning akinesia and episodes of nocturnal hypomobility, many patients use L-dopa on an intermittent or as-needed basis. However, the slow or unpredictable onset of effect limits the clinical benefit. ${ }^{38}$

The addition of monoamine oxidase- $\mathrm{B}$ inhibitors and COMT inhibitors may be helpful in prolonging the duration of the efficacy of each single L-dopa dose. ${ }^{34,39,40}$

In addition to absorption delay due to slowed gastrointestinal transit, circulating diet-derived proteins may interfere with the transit of L-dopa across the blood-brain barrier and in the gut. ${ }^{38,41-43}$ Dietary manipulation, such as reducing the ingestion of protein to minimize L-dopa-protein competition across cellular membrane transporters, may be attempted..$^{35,44}$ Multiple small meals with low fat content and a reduction in the intake of indigestible fiber are considered as effective nonpharmacological strategies for management of gastroparesis. If possible, medications that can slow gastric emptying should be avoided.

Pharmacological treatment of gastroparesis includes the use of prokinetic agents. Dopamine antagonists, such as domperidone and metoclopramide, can also reduce gastric emptying time. Compared to metoclopramide, domperidone does not cross the blood-brain barrier, consequently having minimal effects on the central nervous system, while at the same time significantly improving gastric emptying without affecting PD motor symptoms. ${ }^{14,25,27}$

Long-acting dopamine agonists allow more stable and continuous dopaminergic stimulation (CDS) and improve nocturnal disability. In previous studies, cabergoline, in particular, appeared to be more effective than the L-dopa controlled-release formulation in relieving nocturnal painful dystonia, nocturnal and morning akinesia, and early morning dystonia. ${ }^{45-48}$ Surprisingly, this improvement was associated with a significant increase in the number of awakenings and stage shifts, as shown by polysomnography. The functional significance of this finding remains uncertain ${ }^{49}$ (Table 1).

Bromocriptine, in combination with lower doses of L-dopa, resulted in therapeutic response equal to that achieved with high-dose L-dopa alone, but with significantly fewer end-of-dose failures and dyskinesia. At the end of 5 years, early combination of L-dopa and bromocriptine resulted in a reduced frequency of early morning akinesia and dose-related freezing of gait episodes..$^{50,51}$

More recently, continuous 24-hour delivery of a dopamine agonist has been reported as an attractive option for the management of PD patients with end-of-dose symptom deterioration and specific complaints of nocturnal and early morning motor impairment. ${ }^{52}$

Moreover, prolonged release of dopamine agonists medications (rotigotine, ropinirole, pramipexole) has been associated with significantly less early morning OFF periods compared with L-dopa therapy only. ${ }^{3}$

In 2010, the RECOVER study, a large-scale, double-blind, randomized trial reported 24-hour transdermal rotigotine treatment to be associated with significant benefits versus placebo in the management of early morning motor impairment and nocturnal sleep disturbances. Rotigotine was also associated with improvements in nighttime disabilities (such as limb restlessness, immobility, pain, and cramps), and possibly dopaminergic nonmotor daytime symptoms (such as fatigue and mood) as well..$^{53}$ In addition, the transdermal route bypasses the gastrointestinal tract and its associated motor fluctuations.

An improvement in sleep associated with rotigotine may be the result of its effect on curbing nocturnal motor symptoms: limb restlessness, urge to move arms or legs, painful posturing in the morning, and tremor on awakening. Likewise, reported improvement in painful posturing in the morning may be the result of an early morning improvement in akinesia and dystonia. ${ }^{53}$ Moreover, transdermal rotigotine demonstrated efficacy and safety as monotherapy in early PD and in reducing "OFF" hours in L-dopa-treated patients with advanced PD. ${ }^{54,55}$ 
Table I Studies on the treatments managing morning akinesia

\begin{tabular}{|c|c|c|c|}
\hline Authors & Proposed treatments & Pros & Cons \\
\hline $\begin{array}{l}\text { Baas and Schueler }{ }^{45} \\
\text { Högl et al }{ }^{49}\end{array}$ & Cabergoline & $\begin{array}{l}\text { More effective than the CR-L-dopa in relieving } \\
\text { nocturnal painful dystonia, nocturnal and } \\
\text { morning akinesia, and early morning dystonia }\end{array}$ & $\begin{array}{l}\text { Increase in the number of } \\
\text { awakenings and stage shifts, and } \\
\text { ergot-derived drug adverse events }\end{array}$ \\
\hline $\begin{array}{l}\text { Rinne }^{50} \\
\text { Rinne }^{51}\end{array}$ & Bromocriptine + L-dopa & $\begin{array}{l}\text { Reduced frequency of early morning akinesia and } \\
\text { dose-related freezing of gait episodes }\end{array}$ & Ergot-derived drug adverse events \\
\hline $\begin{array}{l}\text { Giladi et } \mathrm{al}^{52} \\
\text { Trenkwalder et } \mathrm{al}^{53}\end{array}$ & Rotigotine & $\begin{array}{l}\text { Benefit in early morning motor impairment and } \\
\text { sleep disturbances; transdermal administration }\end{array}$ & $\begin{array}{l}\text { Primes/worsens dyskinesia; ICD; } \\
\text { cutaneous reactions }\end{array}$ \\
\hline $\begin{array}{l}\text { Chaudhuri et a }{ }^{56} \\
\text { Poewe et al }{ }^{57}\end{array}$ & $\begin{array}{l}\text { Mirapexin and } \\
\text { ropinirole }\end{array}$ & Improvements in sleep disturbances & $\begin{array}{l}\text { Primes/worsens dyskinesia; } \\
\text { reduced absorption due to oral } \\
\text { administration }\end{array}$ \\
\hline $\begin{array}{l}\text { Trosch et } \mathrm{al}^{58} \\
\text { Pfeiffer et } \mathrm{al}^{59}\end{array}$ & Apomorphine & $\begin{array}{l}\text { Rapid and reliable time-to-ON in patients with } \\
\text { morning akinesia }\end{array}$ & $\begin{array}{l}\text { Self- administration of subcutaneous } \\
\text { injection }\end{array}$ \\
\hline Zibetti et $a^{61}$ & LCIG & $\begin{array}{l}\text { Improvement of nocturnal sleep quality, } \\
\text { pain, muscle cramps, restlessness, and painful } \\
\text { posturing in the morning }\end{array}$ & $\begin{array}{l}\text { High costs, patients selection, } \\
\text { surgical risks }\end{array}$ \\
\hline $\begin{array}{l}\text { Arnulf et } \mathrm{al}^{62} \\
\text { Hjort et } \mathrm{al}^{63} \\
\text { Derrey et } \mathrm{al}^{64}\end{array}$ & STN DBS & $\begin{array}{l}\text { Improvement of sleep architecture and } \\
\text { quality; alleviation of "OFF period" dystonia } \\
\text { after microlesion effect produced by surgical } \\
\text { intervention }\end{array}$ & $\begin{array}{l}\text { High costs, patients selection, } \\
\text { surgical risks }\end{array}$ \\
\hline
\end{tabular}

Abbreviations: L-dopa, levodopa; CR-L-dopa, controlled release levodopa; LCIG, levodopa/carbidopa intestinal gel; STN DBS, subthalamic nuclei deep brain stimulation; ICD, impulse control disorder.

Significant improvements in sleep disturbances have also been recorded with prolonged-release formulations of ropinirole ${ }^{54,56}$ and pramipexole..$^{54,57}$ Though these medications have shown their efficacy and safety in advanced PD, ${ }^{56,57}$ like L-dopa, they are administered orally and their capacity of inducing motor complication is low. In fact, as with all dopaminergic drugs, they may trigger the onset or worsen dyskinesias..$^{40}$

Apomorphine is a potent short-acting dopamine D1 and D2 receptor agonist that can be administered subcutaneously and is currently being used for the management of sudden, unexpected and refractory L-dopa-induced OFF states in fluctuating PD either as intermittent rescue injections or continuous infusions. ${ }^{58-60}$ Apomorphine injections may be helpful in treating morning akinesia, since time-to-ON should not be affected by delayed gastric emptying due to gastroparesis. The ongoing Phase IV, multicenter, open-label AM-IMPAKT trial is investigating whether subcutaneous apomorphine injection on awakening can provide improvement in motor and NMSs in PD patients with morning akinesia. Interim results suggest that apomorphine injection as an adjunctive therapy may provide a rapid and reliable time-to-ON in patients with morning akinesia, resulting in significant improvements in $\mathrm{QoL}^{3,14}$ (Table 1).

CDS is a valid strategy in controlling both motor and NMSs in PD. A recent study on a small number of patients reported that subjective measures of sleep quality improved substantially with L-dopa/carbidopa intestinal gel (LCIG) infusion in advanced PD. Additionally, nocturnal sleep improved in all patients treated with LCIG compared with previous oral therapy. In particular, ameliorations in nocturnal sleep quality, pain, muscle cramps, restlessness, and painful posturing in the morning were reported. ${ }^{61}$

Another small study reported improvements in sleep architecture and quality, along with an increase in total sleep time (up to $47 \%$ ) even in patients treated with subthalamic nuclei (STN) deep brain stimulation (DBS). ${ }^{62,63}$ Moreover, an alleviation of "OFF" dystonia was registered after the microlesion effect produced by STN DBS surgical intervention. In this group of 30 patients, the morning of the third day following STN implantation, after at least a 12-hour withdrawal of dopaminergic treatment and before the programmable pulse generator was switched on, a significant clinical improvement was observed. ${ }^{64}$ Motor score of Unified Parkinson's Disease Rating Scale improved by $27 \%$ and 12 patients reported complete relief of their symptoms in the immediate postoperative period, remaining free of painful off-period dystonia throughout the 6-month follow-up period. ${ }^{64}$

Yet, larger and more specific studies performed over longer periods of time are needed to fully evaluate the beneficial effects of LCIG therapy and STN DBS on both sleep and early morning dystonia. 


\section{Discussion}

Morning akinesia is one of the most common and earliest motor complications in PD patients, affecting almost all stages of the disease. Its physiopathology is complex and even if the fluctuations of L-dopa levels in plasma can be considered as the primary trigger, nondopaminergic pathways are also believed to play underlying roles in both its maintenance and often unpredictable manifestation.

Delayed time-to-ON after the first L-dopa dose has been studied and addressed in many different ways. Optimizing dose and timing of standard L-dopa plus controlled-release L-dopa formulations alone before sleep may offer benefit. Moreover, low-protein, low-fat multiple small meals during the day may help speed up gastric transit along with a prokinetic regimen, such as domperidone. Liquid L-dopa formulations may lead to a faster intestinal absorption without compromising the benefit associated with tablets.

Prompt analyses of other NMSs, such as sleep disorders, should be performed. Insomnia and sleep fragmentation are known to worsen early morning motor functions and prolong time-to-ON. Recommendations concerning sleep hygiene and behavioural therapy ${ }^{65,66}$ may be sufficient to improve QoL.

Prolonged-release dopamine agonist add-on treatments can provide a continuous, more physiologic dopaminergic stimulation, along with improvements in NMSs including sleep disorders.

Small doses of subcutaneous apomorphine, when administered as needed, can rapidly reverse OFF states. However, an early morning subcutaneous self-pen injection in disabled advanced PD patients could be troublesome. Limited evidence is available for ameliorating sleep disorders and early morning motor functions with CDS by LCIG and STN DBS.

The dopaminergic oral treatment alone has been reported $^{3,23,54}$ to be inadequate in providing benefit for morning akinesia. A treatment based on a more continuous stimulation could improve this benefit. Specifically, a continuous stimulation would lead to a sustained delivery of treatment over time.

\section{Disclosure}

The authors report no conflicts of interest in this work.

\section{References}

1. Aquino CC, Fox SH. Clinical spectrum of levodopa-induced complications. Mov Disord. 2015;30(1):80-89.
2. Chapuis S, Ouchchane L, Metz O, Gerbaud L, Durif F. Impact of the motor complications of Parkinson's disease on the quality of life. Mov Disord. 2005;20(2):224-230.

3. Rizos A, Martinez-Martin P, Odin P, et al. Characterizing motor and non-motor aspects of early-morning off periods in Parkinson's disease: an international multicenter study. Parkinsonism Relat Disord. 2014;20(11):1231-1235.

4. Storch A, Schneider CB, Wolz M, et al. Nonmotor fluctuations in Parkinson disease: severity and correlation with motor complications. Neurology. 2013;80(9):800-809.

5. Chaudhuri K, Healy D, Schapira A. Non-motor symptoms of Parkinson's disease: diagnosis and management. Lancet Neurol. 2006;5(3):235-245.

6. Wetter TC, Collado-Seidel V, Pollmächer T, Yassouridis a, Trenkwalder C. Sleep and periodic leg movement patterns in drug-free patients with Parkinson's disease and multiple system atrophy. Sleep. 2000;23(3):361-367.

7. Factor SA, McAlarney T, Sanchez-Ramos JR, Weiner WJ. Sleep disorders and sleep effect in Parkinson's disease. Mov Disord. 1990;5(4):280-285.

8. Garcia-Borreguero D, Larrosa O, Bravo M. Parkinson's disease and sleep. Sleep Med Rev. 2003;7(2):115-129.

9. Parkes JD. Variability in Parkinson's disease; clinical aspects, causes and treatment. Acta Neurol Scand Suppl. 1983;95:27-35.

10. Nutt JG, Gancher ST, Woodward WR. Does an inhibitory action of levodopa contribute to motor fluctuations? Neurology. 1988;38(10):1553-1557.

11. Nutt JG, Woodward WR, Hammerstad JP, Carter JH, Anderson JL. The "on-off" phenomenon in Parkinson's disease. Relation to levodopa absorption and transport. N Engl J Med. 1984;310(8):483-488.

12. Pfeiffer RF. Gastrointestinal, urological, and sexual dysfunction in Parkinson's disease. Mov Disord. 2010;25:94-97.

13. Heetun ZS, Quigley EMM. Gastroparesis and Parkinson's disease: a systematic review. Parkinsonism Relat Disord. 2012;18(5): $433-440$.

14. Isaacson SH, Chaudhuri KR. Morning akinesia and the potential role of gastroparesis - Managing delayed onset of first daily dose of oral levodopa in patients with Parkinson's disease. Eur Neurol Rev. 2013;8(2):82-84.

15. Woitalla D, Goetze O. Treatment approaches of gastrointestinal dysfunction in Parkinson's disease, therapeutical options and future perspectives. J Neurol Sci. 2011;310(1-2):152-158.

16. Martinez-Martin P, Rodriguez-Blazquez C, Kurtis MM, Chaudhuri KR. The impact of non-motor symptoms on health-related quality of life of patients with Parkinson's disease. Mov Disord. 2011;26(3):399-406.

17. Tanaka $Y$, Kato $T$, Nishida $H$, et al. Is there a delayed gastric emptying of patients with early-stage, untreated Parkinson's disease? An analysis using the 13C-acetate breath test. J Neurol. 2011;258:421-426.

18. Kurlan R, Rothfield KP, Woodward WR, et al. Erratic gastric emptying of levodopa may cause "random" fluctuations of parkinsonian mobility. Neurology. 1988;38(3):419-421.

19. Djaldetti R, Baron J, Ziv I, Melamed E. Gastric emptying in Parkinson's disease: patients with and without response fluctuations. Neurology. 1996;46(4):1051-1054.

20. Hardoff R, Sula M, Tamir A, et al. Gastric emptying time and gastric motility in patients with Parkinson's disease. Mov Disord. 2001;16(6):1041-1047.

21. Nyholm D, Lennernas H. Irregular gastrointestinal drug absorption in Parkinson's disease. Expert Opin Drug Metab Toxicol. 2008;4(2): 193-203.

22. Doi H, Sakakibara R, Sato M, et al. Plasma levodopa peak delay and impaired gastric emptying in Parkinson's disease. J Neurol Sci. 2012;319(1-2):86-88.

23. Chaná P, Kuntsmann C, Reyes-Parada M, Sáez-Briones P. Delayed early morning turn "ON" in response to a single dose of levodopa in advanced Parkinson's disease: pharmacokinetics should be considered. J Neurol Neurosurg Psychiatry. 2004;75:1782-1783. 
24. Müller T, Erdmann C, Bremen D, et al. Impact of gastric emptying on levodopa pharmacokinetics in Parkinson disease patients. Clin Neuropharmacol. 2006;29(2):61-67.

25. Jost WH. Gastrointestinal motility problems in patients with Parkinson's disease. Effects of antiparkinsonian treatment and guidelines for management. Drugs Aging. 1997;10:249-258.

26. Valenzuela JE, Defilippi C, Diaz G, Navia E, Merino Y. Effect of dopamine on human gastric and pancreatic secretion. Gastroenterology. 1979;76(2):323-326.

27. Lertxundi U, Peral J, Mora O, Domingo-Echaburu S, MartínezBengoechea MJ, García-Moncó JC. Antidopaminergic therapy for managing comorbidities in patients with Parkinson's disease. Am J Health Syst Pharm. 2008;65(5):414-419.

28. Chaudhuri KR, Odin P, Antonini A, Martinez-Martin P. Parkinson's disease: the non-motor issues. Parkinsonism Relat Disord. 2011;17(10): $717-723$.

29. Marsden CD, Parkes JD. Success and problems of long-term levodopa therapy in Parkinson's disease. Lancet. 1977;309:345-349.

30. Obeso JA, Rodriguez-Oroz MC, Chana P, Lera G, Rodriguez M, Olanow CW. The evolution and origin of motor complications in Parkinson's disease. Neurology. 2000;55:13-23.

31. Group PS. Impact of deprenyl and tocopherol treatment on Parkinson's disease in DATATOP patients requiring levodopa. Parkinson Study Group. Ann Neurol. 1996;39(1):37-45.

32. Group PS. Pramipexole vs Levodopa as initial treatment for Parkinson disease: a Randomized Controlled Trial. JAMA. 2000;284(15): 1931-1938

33. Koller WC, Pahwa R. Treating motor fluctuations with controlled-release levodopa preparations. Neurology. 1994;44(7 Suppl 6):S23-S28.

34. Melamed E, Zoldan J, Galili-Mosberg R, Ziv I, Djaldetti R. Current management of motor fluctuations in patients with advanced Parkinson's disease treated chronically with levodopa. J Neural Transm Suppl. 1999;56:173-183.

35. Stocchi F, Bonamartini A, Vacca L, Ruggieri S. Motor fluctuations in levodopa treatment: clinical pharmacology. Eur Neurol. 1996;36(Suppl 1): 38-42.

36. Koller WC. Management of motor fluctuations in Parkinson's disease. Eur Neurol. 1996;36(Suppl 1):43-48.

37. Swope DM. Rapid treatment of "wearing off" in Parkinson's disease. Neurology. 2004;62(6 Suppl 4):S27-S31.

38. Obering CD, Chen JJ, Swope DM. Update on apomorphine for the rapid treatment of hypomobility ("Off") episodes in Parkinson's disease. Pharmacotherapy. 2006;26(6):840-852.

39. Heinonen EH, Rinne UK. Selegiline in the treatment of Parkinson's disease. Acta Neurol Scand Suppl. 1989;126:103-111.

40. Tambasco N, Simoni S, Marsili E, et al. Clinical aspects and management of levodopa-induced dyskinesia. Parkinsons Dis. 2012;2012:745947.

41. Bracco F, Malesani R, Saladini M, Battistin L. Protein redistribution diet and antiparkinsonian response to levodopa. Eur Neurol. 1991;31(2):68-71.

42. Robertson DR, Higginson I, Macklin BS, Renwick AG, Waller DG, George CF. The influence of protein containing meals on the pharmacokinetics of levodopa in healthy volunteers. Br J Clin Pharmacol. 1991;31(4):413-417.

43. Brannan T, Martinez-Tica J, Yahr MD. Effect of dietary protein on striatal dopamine formation following L-dopa administration: an in vivo study. Neuropharmacology. 1991;30(10):1125-1127.

44. Jankovic J. Complications and limitations of drug therapy for Parkinson's disease. Neurology. 2000;55(12):S2-S6.

45. Baas HK, Schueler P. Efficacy of cabergoline in long-term use: results of three observational studies in 1,500 patients with Parkinson's disease. Eur Neurol. 2001;46(Suppl 1):18-23.

46. Pastor P, Tolosa E. [Cabergoline in the treatment of Parkinson's disease]. Neurologia. 2003;18(4):202-209. Spanish.
47. Chaudhuri KR, Clough C. Subcutaneous apomorphine in Parkinson's disease. BMJ. 1998;316(7132):641.

48. Tambasco N, Muti M, Chiarini P, et al. Entacapone reduces cortical activation in Parkinson's disease with wearing-off: A f-MRI study. PLoS One. 2014;9(5):e96806.

49. Högl B, Rothdach A, Wetter TC, Trenkwalder C. The effect of cabergoline on sleep, periodic leg movements in sleep, and early morning motor function in patients with Parkinson's disease. Neuropsychopharmacology. 2003;28(10):1866-1870.

50. Rinne UK. Combined bromocriptine-levodopa therapy early in Parkinson's disease. Neurology. 1985;35(8):1196-1198.

51. Rinne UK. Early combination of bromocriptine and levodopa in the treatment of Parkinson's disease: a 5-year follow-up. Neurology. 1987;37(5):826-828.

52. Giladi N, Fichtner A, Poewe W, Boroojerdi B. Rotigotine transdermal system for control of early morning motor impairment and sleep disturbances in patients with Parkinson's disease. J Neural Transm. 2010;117(12):1395-1399.

53. Trenkwalder C, Kies B, Rudzinska M, et al. Rotigotine effects on early morning motor function and sleep in Parkinson's disease: a doubleblind, randomized, placebo-controlled study (RECOVER). Mov Disord. 2011;26(1):90-99.

54. Stocchi F, Stirpe P. The relevance of dopaminergic level in nocturnal disability in Parkinson's disease: implications of continuous dopaminergic stimulation at night to treat the symptoms. J Neural Transm. 2014;121(Suppl 1):79-83.

55. Sanford M, Scott LJ. Rotigotine transdermal patch: a review of its use in the treatment of Parkinson's disease. CNS Drugs. 2011;25(8): 699-719.

56. Chaudhuri KR, Martinez-Martin P, Rolfe K a, et al. Improvements in nocturnal symptoms with ropinirole prolonged release in patients with advanced Parkinson's disease. Eur J Neurol. 2012;19(1):105-113.

57. Poewe WH, Rascol O, Quinn N, et al. Efficacy of pramipexole and transdermal rotigotine in advanced Parkinson's disease: a doubleblind, double-dummy, randomised controlled trial. Lancet Neurol. 2007;6(6):513-520.

58. Trosch RM, Silver D, Bottini PB. Intermittent subcutaneous apomorphine therapy for "off” episodes in Parkinson's disease: a 6-month open-label study. CNS Drugs. 2008;22(6):519-527.

59. Pfeiffer RF, Gutmann L, Hull KL, Bottini PB, Sherry JH. Continued efficacy and safety of subcutaneous apomorphine in patients with advanced Parkinson's disease. Park Relat Disord. 2007;13(2):93-100.

60. Wüllner U, Fuchs G, Reketat N, Randerath O, Kassubek J. Requirements for Parkinson's disease pharmacotherapy from the patients' perspective: a questionnaire-based survey. Curr Med Res Opin. 2012;28(7): 1239-1246.

61. Zibetti M, Rizzone M, Merola A, et al. Sleep improvement with levodopa/carbidopa intestinal gel infusion in Parkinson disease. Acta Neurol Scand. 2013;127(5):28-32.

62. Arnulf I, Bejjani BP, Garma L, et al. Improvement of sleep architecture in PD with subthalamic nucleus stimulation. Neurology. 2000;55(11):1732-1734.

63. Hjort N, Østergaard K, Dupont E. Improvement of sleep quality in patients with advanced Parkinson's disease treated with deep brain stimulation of the subthalamic nucleus. Mov Disord. 2004;19(2):196-199.

64. Derrey S, Lefaucheur R, Chastan N, et al. Alleviation of off-period dystonia in Parkinson disease by a microlesion following subthalamic implantation. J Neurosurg. 2010;112(6):1263-1266.

65. Cantor L. Treating Sleep Disorders: Principles and Practice of Behavioral Sleep Medicine. Prim Care Companion J Clin Psychiatry. 2005;7:37.

66. Belenky G, Wu LJ, Jackson ML. Occupational sleep medicine: practice and promise. Prog Brain Res. 2011;190:189-203. 
Journal of Parkinsonism \& Restless Legs Syndrome

\section{Publish your work in this journal}

Dovepress

Journal of Parkinsonism and Restless Legs Syndrome is an online, open access, peer-reviewed journal. The journal publishes review articles, historical reviews, original research articles, case reports, letters to the editor, clinical teaching cases, neuroradiology highlights, neuropathology highlights, neuropsychiatry highlights, autobiographies, conference proceedings, abstracts and book reviews. The manuscript management system is completely online and includes a very quick and fair peer-review system, which is all easy to use. Visit http://www.dovepress.com/ testimonials.php to read real quotes from published authors.

Submit your manuscript here: http://www.dovepress.com/journal-of-parkinsonism--restless-legs-syndrome-journal 